\title{
WESTERN RED DAMSELFLIES FOUND AT TWO NEW LOCATIONS IN 2015
}

\section{Lorne Duczek}

30 Birch Place,Saskatoon, SK S7N 2P6 duczekl@sasktel.net

On July 5, 2015, western red damsel (Amphiagrion abbreviatum) damselflies were found in the Crooked Lake Fen, a Nature Saskatchewan sanctuary, at the calcareous pools in the northwest sector (N50.65068 W102.84033). On July 8,2015 , they were also found at a small spring near the east entrance (N49.20542 W109.02536) of Old Man on His Back Conservation Area west of Claydon. Several mating pairs and individuals were seen at both locations.

This species has only been found at widely dispersed locations in
: Saskatchewan. It was recorded near Roche Percee in the southeast in 1980 and at two locations south of Maple Creek prior to 2005. It was discovered at a fen at Petturson's Ravine in Saskatoon in 2013'.

The western red damsel is a small damselfly, 24-28 mm long, and its bright red abdomen distinguishes it from other small damselflies in Saskatchewan, which are mainly blue. It has very specific habitat requirements that include small springs and fens with open water and low vegetation. Adults may be present at these habitats from late June to early August. The western red damsel is a rare species as sightings are sparse across the prairies. Its presence at the Crooked
: Lake Fen and at Old Man on His Back might serve to highlight the conservation value of these natural landscapes.

1. Duczek L, Taylor P, Salisbury C, Salisbury L (2014) Western Red Damsel at Petturson's Ravine in Saskatoon Saskatchewan in 2013. Blue Jay 72: 81-85.

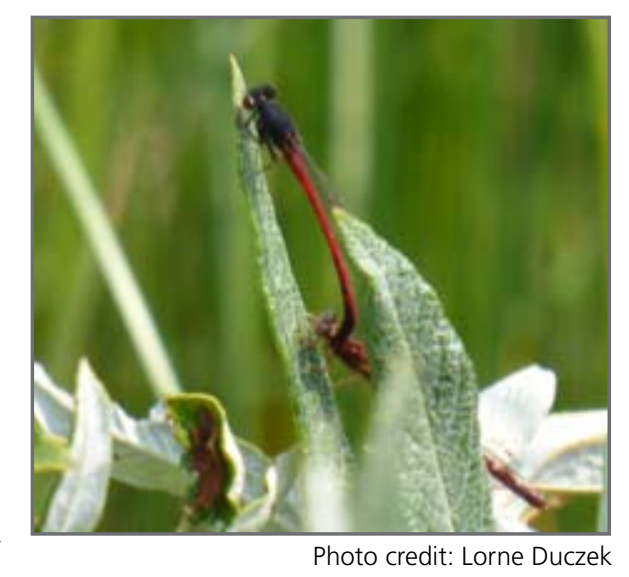

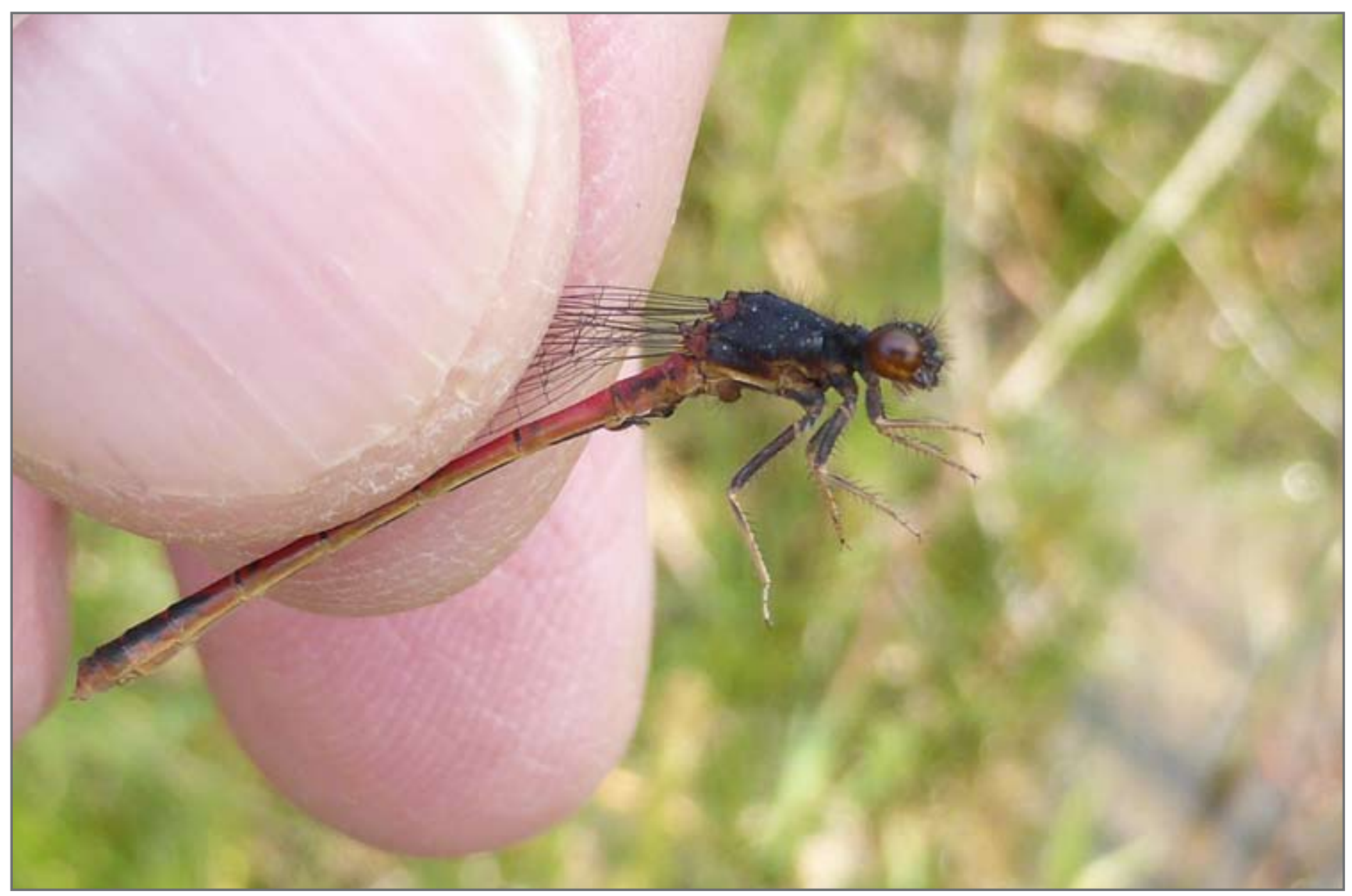

